\title{
Assessment of the Gail Model in Estimating the Risk of Breast Cancer: Effect of Cancer Worry and Risk in Healthy Women
}

\author{
Abdulbari Bener ${ }^{1,2,3 *}$, Cem Cahit Barışık ${ }^{4}$, Ahmet Acar ${ }^{1}$, Yaşar Özdenkaya ${ }^{5}$
}

\begin{abstract}
Background: There has been substantial interest in developing methods to predict the risk of breast cancer. The Gail model is one the first model have been widely used to identify women at higher risk of breast cancer. Aim: This study aimed to determine the 5-year and the general life-time risk of breast cancer and also to determine breast cancer predictors in women using the Gail model. Methods: We used the Gail model to estimate the risk of breast cancer in female Turkish outpatients aged above 35 years in this cross-sectional study. Age, life-style habits, breast-feeding duration, family history of breast cancer, and body mass index were compared between high and low-risk subjects. We have performed the Patient Health Questionnaire 9-item (PHQ-9) and the Generalized Anxiety Disorder 7-item (GAD-7) tools on patients regarding depression and anxiety. We also assessed the association of these covariates with the estimated risk of breast cancer in multivariate linear regression analysis. Results: We enrolled 1065 subjects with a mean age of $52.9 \pm 8.4$ years. The mean of the five-year risk for breast cancer was $1.33 \% \pm 0.6$. Meanwhile, the mean of lifetime risks for breast cancer was $10.15 \% \pm 3.18$, respectively. Nearly one-third of the participants had one child, $55.9 \%$ had breast-fed their children more than six months. Meanwhile, $18.5 \%$ of the subjects had a high depression score, $15.2 \%$ had a high anxiety score. Higher age, age at first birth, and parity; lower age at menarche; presence of menopause and family history of breast cancer were higher in the high-risk group. Higher age, and age at first birth; lower age at menarche; family history of breast cancer, presence of menopause, and parity were independently associated with higher breast cancer risk. Conclusion: We identified certain risk factors for breast cancer in our study population and Gail model is a reliable and useful breast cancer risk prediction model for clinical decision-making. This study contributes to the body of evidence in order to facilitate early detection and better plan for possible malignancies in Turkish population.
\end{abstract}

Keywords: Breast cancer- Gail model risk assessment- lifestyle- predictor- risk factors- consanguinity- Turkish women

Asian Pac J Cancer Prev, 20 (6), 1765-1771

\section{Introduction}

Breast cancer is the most commonly diagnosed cancers in women worldwide and its account for $29 \%$ of all new cancers in women at 2015 (Siegel et al., 2015) with high morbidity and mortality rates. Risk assessment tools estimating the individual's absolute risk for developing breast cancer and identifying the women at high level of risk are crucial for decision-making about prevention and screening (Globocan 2012; World Health Organization, WHO, 2014).

Among Turkish women, breast cancer is the most common cancer and the most common cause of cancer related death (Ministry of Public Health, Turkey, Ulusoy et al., 2010; Erbil et al., 2015). Investigators have suggested various models to estimate the risk of breast cancer using several risk factors identified in epidemiological studies (Gail et al., 1989). Among these tools, the Gail model, which utilizes the risk factors identified in the Breast Cancer Detection Demonstration Project (BCDD) in 1989, is the most commonly used one (Gail et al., 1989; Ulusoy et al., 2010; Erbil et al., 2015) and has been modified (Costantino at al., 1999). About 5\% to $10 \%$ of breast cancers are thought to be hereditary, caused by abnormal genes passed from parent to child (Claus et al., 1994; Bener et al., 2010). Genetic factors play an important role in the pathogenesis of breast cancer and family history of breast cancer is a well-known risk factor (Bener et al., 2010, Bener et al., 2017). Given the benefits of early diagnosis and prevention of breast cancer, implementation of breast cancer screening is crucial, especially for "high-risk" women (Tyrer et al., 2005; Gail et al., 2007; Adams -Campbell et al., 2009; Pace and Keating 2014). The Gail model incorporates six

${ }^{1}$ Department of Biostatistics and Medical Informatics, Cerrahpaşa Faculty of Medicine, Istanbul University, ${ }^{3}$ Istanbul Medipol University, International School of Medicine, ${ }^{4}$ Department of Radiology and Pathology, ${ }^{5}$ Department of Surgery, Medipol School of Medicine, Istanbul Medipol University, Istanbul, Turkey, ${ }^{2}$ Department of Evidence for Population Health Unit, School of Epidemiology and Health Sciences, University of Manchester, Manchester, UK. *For Correspondence: abdulbari.bener@istanbul.edu.tr 
breast cancer risk factors, namely: age, age at menarche, age at first live birth, number of breast biopsies, history of atypical hyperplasia, and number of first-degree relatives with breast cancer (Gail et al., 1989; Claus et al., 1994; Costantino at al., 1999).

One of the advantages of Gail model (Park et al., 2013; Khazaee-Pool et al., 2016; Mirghafourvand et al., 2016) is the extensive validation in various female populations for more than two decades. We aimed to estimate 5-year and life-time risk of breast cancer and determine risk factors associated with higher breast cancer risk in Turkish population.

\section{Materials and Methods}

This cross sectional study was conducted among the outpatients patients registered in internal medicine clinics, surgery, ophthalmology of outpatient clinics, Obstetrics - Gynecology - Medipol International Health Centers during the study period from June 2016 to March 2018 among Turkish citizens above 35 years of age. IRB ethical approval for this study was provided by the Istanbul Medipol University and conducted in accordance with the Declaration of Helsinki. All participants gave consent and approved prior to inclusion in the study.

The sample size calculation was based on previous studies that determined the prevalence of Breast cancer in Turkey (Ulusoy et al., 2010; Erbil et al., 2015) to be between $25 \%-27 \%$, with the $99 \%$ confidence interval and with $2.5 \%$ error of estimation. The minimum sample size for the current study was 1,500 . Subjects were recruited by the systematic 1-in-2 sampling procedure. During the study period, a representative sample of 1,500 women aged 35 years and older was selected, 1,065 (71.0\%) subjects gave consent. Meanwhile, 435 women either refused or were not available to take part in the study due to personal reasons and lack of time.

We have calculated the five-year and life-time risk for breast cancer using Breast Cancer Risk Assessment Tool (BCRAT, 2018) which is based on the Gail model (Gail et al., 1989; National Cancer Institute 2018). According to the Gail model, women with the breast cancer risk of $>1.66 \%$ were considered as high-risk according to the estimated 5-year breast cancer- risk assessment. The Gail Risk Assessments Tool is useful to guess the approximate number of women with a lifetime risk of $\geq 15 \%$ in the general population (Gail et al., 1989; Pace and Keating, 2014).

We calculated the five-year and life-time risk for breast cancer using Breast Cancer Risk Assessment Tool (BCRAT) which is based on the Gail model (Mirghafourvand et al., 2016). BCRAT is an interactive tool which estimates 5-year and lifetime risk for breast cancer. Stratification of risk level is one of the main targets of risk assessment tools which facilitates screening decision and clinical management. According to the Gail model, while a five-year breast cancer risk of less than $1.66 \%$ indicates low risk, an estimated risk of $1.66 \%$ or higher suggests high risk (National Cancer Institute, 2018). We determined the mean 5-year and lifetime risks of our study population and classified the subjects as low- or high-risk if they had a lower or higher risk than the mean of the study population respectively. In this context, a five-year breast cancer risk of $1.33 \%$ or higher and a life-time breast cancer risk of $10.15 \%$ or higher indicated high-risk for this study.

\section{Patient health questionnaire 9-item (PHQ-9)}

Understanding psychological factors relevant to women's participation in breast cancer screening is essential to ensuring that clinical and public health policies and interventions improve breast cancer morbidity and mortality. The PHQ-9 contains nine items referring to criteria for depression (Kroenke et al., 2001) and the answers refer to the past two weeks. The PHQ-9 has been shown to have good reliability and validity (Kroenke et al., 2001). Overall, the PHQ-9 items showed good internal (Cronbach's alpha 0.85 ) reliability. A cut-off score of 10 was established for the PHQ-9 (sensitivity $87 \%$, specificity $89 \%$ ), correctly classifying $86 \%$ of patients with current depression.

\section{Generalized anxiety disorder 7-item (GAD-7)}

The GAD-7 (Spitzer et al., 2006) tool conducted on subjects are asked how often, bothered by each of the seven core symptoms of generalized anxiety disorder and cut-off point of 10 to describe clinical symptoms of anxiety in the sample. The GAD-7 has been shown to have good reliability and validity (Spitzer et al., 2006). Cronbach's alpha in the current study was 0.87 .

Statistical analysis and comparisons are based on Independent Student-t test, Chi-square and Fisher's exact test. Multiple linear stepwise regression analysis performed to predict the 5-year and lifetime breast cancer risk. The level $\mathrm{p}<0.05$ was considered as the cut-off value for significance.

\section{Results}

We assessed content validity, face validity and reliability of the questionnaire in 100 subjects. These tests demonstrated a high level of validity and high degree of reproducibility $($ kappa $=0.87)$. We tested the validation of the pilot survey instruments in 100 subjects. We demonstrated adequate scale reliability with Cronbach's alpha coefficient values higher than 0.70 . The Cronbach's alpha for overall internal reliability was 0.87 .

Table 1 shows the socio-demographic features of the study population. The mean age was $52.94 \pm 8.48$ years. Among the study population, $87.9 \%$ were married, 56.1\% were housewives, $10.2 \%$ were illiterate, and $23.9 \%$ were university graduates. Majority of participants $(57.6 \%)$ had experienced menarche between the ages 12 and 13 years. Nearly two thirds of the study population $(66.4 \%)$ were post-menopausal., Rates of cigarette smoking (17.6\%) and sheesha smoking $(10.0 \%)$ were low.

Table 2 demonstrates life-style and clinical features of the study population. Among the study population, 26.5\% walked 30 minutes per day and $11 \%$ walked 60 minutes per day. Frequency of overweight was $45.6 \%$ and $28.9 \%$ were obese. Nearly one-third of the participants had one 
Table 1. Socio-Demographic Characteristics of Breast Cancer Patients $(\mathrm{N}=1,065)$

\begin{tabular}{|c|c|c|}
\hline Age $[$ Mean \pm SD] & $\begin{array}{c}\mathrm{n} \\
52.94 \pm 8.48\end{array}$ & $\begin{array}{c}\% \\
\text { Range 35-65 }\end{array}$ \\
\hline \multicolumn{3}{|l|}{ Age groups } \\
\hline $35-45$ & 226 & 21.2 \\
\hline $46-55$ & 377 & 35.4 \\
\hline $56-65$ & 462 & 43.4 \\
\hline \multicolumn{3}{|l|}{ Age at menarche } \\
\hline 9-11 Years old & 186 & 17.5 \\
\hline 12-13 Years old & 626 & 58.8 \\
\hline$>14$ Years old & 253 & 23.8 \\
\hline \multicolumn{3}{|l|}{ Menopausal } \\
\hline Pre-menopausal (non-menopause) & 358 & 33.6 \\
\hline Post-menopausal (menopause) & 707 & 66.4 \\
\hline \multicolumn{3}{|l|}{ Marital status } \\
\hline Single & 62 & 5.8 \\
\hline Married & 936 & 87.9 \\
\hline Widow/divorce & 667 & 6.3 \\
\hline \multicolumn{3}{|l|}{ Education level } \\
\hline Illiterate & 109 & 10.2 \\
\hline Primary & 190 & 17.8 \\
\hline Intermediate & 217 & 20.4 \\
\hline Secondary & 303 & 28.5 \\
\hline University or higher & 446 & 23.1 \\
\hline \multicolumn{3}{|l|}{ Occupation } \\
\hline Housewife & 597 & 56.1 \\
\hline Sedentary/Professional & 175 & 16.4 \\
\hline Clerk/Officer/Administrator & 163 & 15.3 \\
\hline Businesswomen & 67 & 6.3 \\
\hline Police / Army/Security Force & 63 & 5.9 \\
\hline \multicolumn{3}{|l|}{ Household Income } \\
\hline Low & 294 & 27.6 \\
\hline Medium & 435 & 40.8 \\
\hline High & 336 & 31.5 \\
\hline \multicolumn{3}{|l|}{ Cigarette smoking } \\
\hline Never & 877 & 82.3 \\
\hline Current smoke & 141 & 13.2 \\
\hline Ex-smoker & 47 & 4.2 \\
\hline \multicolumn{3}{|l|}{ Sheesha Smoking } \\
\hline Yes & 106 & 10.0 \\
\hline No & 959 & 90.0 \\
\hline
\end{tabular}

child. Most of the participants (55.9\%) had breast-fed their children more than six months. While $18.5 \%$ of the subjects had a high depression screen score, $15.2 \%$ had a high anxiety screen score.

The mean of the five-year risk for breast cancer was $1.33 \% \pm 0.6$. Meanwhile, the mean of lifetime risks for breast cancer was $10.15 \% \pm 3.18$, respectively. Table 3 demonstrates socio-demographic features of high-risk and low-risk women in comparison according to their five-year and life-time breast cancer risk. There were significant differences between high-risk and low-risk groups according to five-years and life-time breast cancer risk estimation such as age, age at menarche, age at first birth, family history of cancer, menopausal status, parity (only for five-year risk), BMI, occupation, and level of education according to five-year risk estimation; and age, age at menarche, age at first birth, family history of cancer, menopausal status, and level of education according to life-time risk estimation.

While age, age of first birth, family history, menopausal

Table 2. Life-Style and Clinical Characteristics of Study Sample $(\mathrm{N}=1,065)$

\begin{tabular}{|c|c|}
\hline Variables & $\mathrm{n}(\%)$ \\
\hline \multicolumn{2}{|l|}{ Physical activity walking per-day } \\
\hline 30 Minutes & $282(26.5)$ \\
\hline 60 Minutes & $118(11.0)$ \\
\hline None & $665(62.5)$ \\
\hline \multicolumn{2}{|c|}{ Body Mass index Group-BMI $\left(\mathrm{Kg} / \mathrm{m}^{2}\right)$} \\
\hline $20-24.99 \mathrm{Kg} / \mathrm{m}^{2}$ (Normal) & $272(25.5)$ \\
\hline $25-30 \mathrm{Kg} / \mathrm{m}^{2}$ (Overweight) & $485(45.6)$ \\
\hline$>30 \mathrm{Kg} / \mathrm{m}^{2}$ (Obese) & $308(28.9)$ \\
\hline \multicolumn{2}{|l|}{ Infertility } \\
\hline Yes & $72(6.8)$ \\
\hline No & $993(93.2)$ \\
\hline \multicolumn{2}{|l|}{ Parity } \\
\hline None & $82(7.7)$ \\
\hline$<3$ children & $575(54.0)$ \\
\hline$>3$ children & $408(38.3)$ \\
\hline \multicolumn{2}{|l|}{ Breast-feeding } \\
\hline Yes & $877(82.3)$ \\
\hline No & $188(17.7)$ \\
\hline \multicolumn{2}{|l|}{ Breast-feeding duration } \\
\hline 6 months & $354(33.2)$ \\
\hline$>6$ months & $711(66.8)$ \\
\hline \multicolumn{2}{|l|}{ Consanguineous parents } \\
\hline Yes & $59(5.5)$ \\
\hline No & $1006(94.5)$ \\
\hline \multicolumn{2}{|l|}{ First degree family cancer history } \\
\hline Yes & $62(6.8)$ \\
\hline No & $1003(94.2)$ \\
\hline \multicolumn{2}{|c|}{ Family cancer history more than one } \\
\hline Yes & $71(6.7)$ \\
\hline No & $994(93.3)$ \\
\hline \multicolumn{2}{|l|}{ Mammography screening } \\
\hline Yes & $89(8.4)$ \\
\hline No & $976(91.6)$ \\
\hline \multicolumn{2}{|l|}{ Depression PHQ-9 score * } \\
\hline Score $>10$ & $197(18.5)$ \\
\hline Score $\leq 10$ & $868(81.5)$ \\
\hline \multicolumn{2}{|l|}{ Anxiety GAD-7 score ** } \\
\hline Score $>10$ & $162(15.2)$ \\
\hline Score $\leq 10$ & $903(84.8)$ \\
\hline
\end{tabular}

* Patients were considered depression "screen-positive" if their PHQ-9 score was $>10$; ** Patienats were considered anxiety "screen-positive" if their GAD-7 score was $>10$.

Asian Pacific Journal of Cancer Prevention, Vol 20 
Table 3. Socio-demographic of Patients with Breast Cancer Risk Using Gail Model $(\mathrm{N}=1,065)$

\begin{tabular}{|c|c|c|c|c|c|c|}
\hline & \multicolumn{3}{|c|}{ 5-Year Risk Mean $(1.33 \pm 0.60)$} & \multicolumn{3}{|c|}{ Lifetime Risk Mean $(10.15 \pm 3.18)$} \\
\hline & Low Risk & High Risk $\mathrm{n}(\%)$ & $\mathrm{p}$ value $\mathrm{n}(\%)$ & Low Risk n (\%) & High Risk n (\%) & $\mathrm{p}$ value $\mathrm{n}(\%)$ \\
\hline \multicolumn{7}{|l|}{ Age Groups } \\
\hline $35-45$ & $216(38.4)$ & $10(2.0)$ & & $72(12.3)$ & $154(32.0)$ & \\
\hline $46-55$ & $239(42.5)$ & $138(27.5)$ & $<0.001$ & $186(31.9)$ & $191(39.6)$ & $<0.001$ \\
\hline $56-65$ & $108(19.1)$ & $354(50.5)$ & & $325(55.8)$ & $137(28.4)$ & \\
\hline \multicolumn{7}{|l|}{ Age at Menarche } \\
\hline $9-11$ & $76(13.5)$ & $110(28.3)$ & & $86(14.8)$ & $100(20.7)$ & \\
\hline $12-13$ & $339(63.2)$ & $287(57.2)$ & $<0.001$ & $375(57.5)$ & $291(60.4)$ & $<0.001$ \\
\hline 14 & $148(26.3)$ & $105(20.9)$ & & $162(27.8)$ & $91(18.9)$ & \\
\hline \multicolumn{7}{|l|}{ Age at First Birth } \\
\hline$<20$ & $101(12.9)$ & $10(3.2)$ & & $106(18.2)$ & $11(2.3)$ & \\
\hline $20-24$ & $171(30.4)$ & $56(11.2)$ & $<0.001$ & $185(33.4)$ & $32(6.6)$ & $<0.001$ \\
\hline $25-29$ & $190(33.7)$ & $149(29.7)$ & & $204(35.0)$ & $135(28.0)$ & \\
\hline 30 & $101(12.9)$ & $281(56.0)$ & & $78(13.4)$ & $304(63.1)$ & \\
\hline \multicolumn{7}{|l|}{ Family History } \\
\hline Yes & $42(7.5)$ & $63(12.5)$ & $<0.001$ & $50(8.6)$ & $61(12.7)$ & $<0.001$ \\
\hline No & $521(92.5)$ & $439(87.5)$ & & $533(91.4)$ & $421(87.7)$ & \\
\hline \multicolumn{7}{|l|}{ Menopausal } \\
\hline Pre-menopausal & $315(56.0)$ & $43(8.6)$ & 0.419 & $134(23.0)$ & $224(46.5)$ & $<0.001$ \\
\hline Post-menopausal & $248(44.0)$ & $459(91.4)$ & & $449(77.0)$ & $258(53.5)$ & \\
\hline \multicolumn{7}{|l|}{ Breast-feeding } \\
\hline$<6$ months & $193(34.3)$ & $161(32.1)$ & 0.474 & $196(33.6)$ & $158(32.8)$ & 0.412 \\
\hline 6 months & $370(65.7)$ & $341(67.9)$ & & $387(66.4)$ & $324(67.2)$ & \\
\hline \multicolumn{7}{|l|}{ Consanguinity } \\
\hline Yes & $35(6.2)$ & $24(4.8)$ & 0.043 & $39(6.7)$ & $20(4.1)$ & 0.195 \\
\hline No & $518(93.8)$ & $478(95.2)$ & & $544(93.3)$ & $462(94.9)$ & \\
\hline \multicolumn{7}{|l|}{ Parity } \\
\hline 3 Children & $368(65.4)$ & $289(57.6)$ & $<0.001$ & $357(61.2)$ & $300(76.1)$ & 0.267 \\
\hline$>3$ Children & $195(34.6)$ & $213(42.4)$ & & $226(38.8)$ & $182(23.9)$ & \\
\hline \multicolumn{7}{|l|}{ BMI } \\
\hline $20-24.99 \mathrm{Kg} \backslash \mathrm{m}^{2}$ & $158(28.1)$ & $114(22.7)$ & & $136(23.3)$ & $136(28.2)$ & \\
\hline $25-30 \mathrm{Kg} \backslash \mathrm{m}^{2}$ & $232(41.2)$ & $253(50.4)$ & 0.010 & $283(48.5)$ & $202(41.9)$ & 0.071 \\
\hline$>30 \mathrm{Kg} \backslash \mathrm{m}^{2}$ & $173(30.7)$ & $135(26.9)$ & & $164(28.1)$ & 144 (29.9) & \\
\hline \multicolumn{7}{|l|}{ Breast Biopsies } \\
\hline Yes & $6(1.1)$ & $7(1.4)$ & 0.416 & $7(1.2)$ & $6(1.2)$ & 1.000 \\
\hline No & $557(98.9)$ & 495 (98.6) & & $576(98.9)$ & $476(98.8)$ & \\
\hline \multicolumn{7}{|l|}{ Sheesha Smoking } \\
\hline Yes & $53(9.4)$ & $53(10.6)$ & 0.301 & $52(8.9)$ & $54(11.2)$ & 0.219 \\
\hline No & $510(90.6)$ & $449(89.4)$ & & $531(91.1)$ & $428(88.8)$ & \\
\hline \multicolumn{7}{|l|}{ Cigarette smoking } \\
\hline Yes & $93(16.5)$ & $95(18.9)$ & & $100(17.2)$ & $88(18.3)$ & 0.845 \\
\hline No & $470(83.5)$ & $407(81.1)$ & & $483(82.8)$ & $394(81.7)$ & \\
\hline \multicolumn{7}{|l|}{ Occupation } \\
\hline Housewife & $295(52.4)$ & $302(60.2)$ & & $324(55.6)$ & $273(56.6)$ & \\
\hline Sedentary $\backslash$ Professional & $119(21.1)$ & $56(11.2)$ & & $84(14.4)$ & $91(18.9)$ & 0.114 \\
\hline Clerk $\backslash$ Administrator & $113(20.1)$ & $113(22.5)$ & $<0.001$ & $138(23.6)$ & $88(18.3)$ & \\
\hline Businesswomen & $36(6.4)$ & $31(6.2)$ & & $37(6.3)$ & $30(6.2)$ & \\
\hline \multicolumn{7}{|l|}{ Education Level } \\
\hline Illiterate & $44(7.8)$ & $65(12.9)$ & & $73(12.5)$ & $36(7.5)$ & \\
\hline Primary & $96(17.1)$ & $94(18.7)$ & & $95(16.3)$ & $95(19.7)$ & \\
\hline Intermediate & $114(20.2)$ & $103(20.5)$ & 0.030 & $131(22.5)$ & $86(17.8)$ & $0.00 \mathrm{vf9}$ \\
\hline Secondary & $156(27.7)$ & $147(25.3)$ & & $160(27.4)$ & 143 (29.7) & \\
\hline University or higher & $153(27.2)$ & $83(18.5)$ & & $124(21.3)$ & $122(25.3)$ & \\
\hline
\end{tabular}


Table 4. Regression Results for 5-year and Lifetime Gail Risk

\begin{tabular}{|c|c|c|c|c|}
\hline Independent Variables & Coefficient & Standard Error & $\mathrm{t}$ & p-value \\
\hline \multicolumn{5}{|l|}{ 5-Year Risks } \\
\hline Constant & -0.176 & 0.36 & -1.298 & 0.195 \\
\hline Age & 0.032 & 0.001 & 25.310 & $<0.001$ \\
\hline Age at Menarche & -0.034 & 0.007 & -4.511 & $<0.001$ \\
\hline Age of First Birth & 0.204 & 0.011 & 18.897 & $<0.001$ \\
\hline Family History & -0.134 & 0.035 & -3.732 & $<0.001$ \\
\hline Menopausal & 0.529 & 0.028 & 3.499 & $<0.001$ \\
\hline Parity & 0.076 & 0.020 & 2.878 & 0.004 \\
\hline \multicolumn{5}{|l|}{ Lifetime Risks } \\
\hline Constant & 2.476 & 0.151 & 16.383 & $<0.001$ \\
\hline Age & -0.025 & 0.002 & -10.154 & $<0.001$ \\
\hline Age at Menarche & -0.034 & 0.008 & -4.423 & $<0.001$ \\
\hline Age of First Birth & 0.273 & 0.011 & 23.761 & $<0.001$ \\
\hline Menopausal & 0.261 & 0.031 & -8.328 & $<0.001$ \\
\hline Family History & -0.108 & 0.038 & -2.861 & 0.004 \\
\hline Parity & 0.056 & 0.024 & 2.319 & 0.021 \\
\hline
\end{tabular}

status, and parity were positively related with five-year breast cancer risk, age at menarche was inversely related with five-year breast cancer risk according to multivariate linear regression analysis (Table 4). Variables positively associated with life-year breast cancer risk were age of first birth, family history, menopausal status, and parity; while variables inversely related with life-year breast cancer risk consisted of age and age at menarche according to multivariate linear regression analysis.

\section{Discussion}

The Gail model (Gail et al 1989; Costantino et al., 1999; Gail et al., 2007; Adams -Campbell et al., 2009). is most commonly used in estimation of risk of breast cancer. It is important to accurately assess breast cancer risk to take preventive measures and make decision on screening procedures. Breast cancer is the most common type of cancer and accounts for the greatest number of cancer-related death among women in Turkey (Ulusoy et al., 2010; Erbil et al., 2015). The Gail model might overestimate breast cancer risk for Asian and Middle-Eastern women. Thus, it is needed to revalidate the Gail model in these populations. In this study, we aimed to revalidate the Gail model using data of Turkish women, and subsequently update and revalidate the Turkish version of the Gail model using our data. The results of our study indicate that Turkish version of the Gail model is valid and provides clinically relevant information. Age, age of first birth, age at menarche, family history, menopausal status, and parity seems to be independently associated with estimated breast cancer risk.

In Iran study (Khazaee-Pool et al., 2016), the mean five-year risk of breast cancer for all participants was $1.608 \pm 0.729 \%$ (range $0.2 \pm 13.8 \%$ ). The mean lifetime risk of breast cancer was $11.705 \pm 3.91 \%$ (range $0.654 .7 \%$ ). Similarly, in Turkey, analysis revealed that the mean of the five-year risk for breast cancer was $1.33 \% \pm 0.6$. and meanwhile, the mean of lifetime risks for breast cancer was $10.15 \% \pm 3.18$, which is consistent with the Iranian results.

The best-known statistical model available for predicting an individual woman's chance of developing breast cancer is that derived using information from regularly screened Caucasian women from the United States participating in the Breast Cancer screening and detection project (Gail et al 1989; Costantino et al., 1999; Gail et al., 2007; Adams -Campbell et al., 2009). The Gail model might overestimate the risk of and development of breast cancer in other populations in which other races predominate (Novotny et al., 2006; Andreeva and Pokhrel 2013; Wang et al., 2018). However, utilization of the Gail model for Turkish population and other populations with white women predominance might provide more accurate estimations (Tice et al., 2005; Min et al., 2014; Wang et al., 2018). Accordingly, the five-year and life-time estimated risk for breast cancer was not higher in our study than different studies (Tice et al., 2005; Min et al., 2014; Khazaee-Pool et al., 2016, Wang et al., 2018). Unfortunately, the Gail model for breast cancer risk prediction of consanguineous marriages for fist degree and second-degree relatives is not included as a risk factor. On the other hand, the Claus model (Claus et al., 1994) takes presence of both first and second-degree relatives with breast cancer and their age at diagnosis into account as risk factors. BRCAPRO model utilizes Bayesian statistics and Mendelian approaches and considers family history of bilateral breast cancer and ovarian cancer as risk factors (Bener et al., 2010; 28-30). The Tyrer-Cuzick (Tyrer et al., 2004) estimated 10-year risk model which also provides information about the possibility of a breast cancer susceptibility gene mutation (Berry et al., 2002; McPherson et al., 2000).

Estimation of breast cancer risk is essential in the management of screening and prevention of this cancer. Closer screening may be beneficial in high-risk 
individuals. Screening with mammography has provided an important decrease in breast cancer mortality in women over 50 years old in Western countries (Gail et al., 1989; Claus et al., 1994; Costantino at al., 1999; McPherson et al., 2000; Berry et al., 2002). However, the advantage of screening is less clear for younger women. It would be better to individualize breast cancer screening for women under 50 years old. In this context, risk estimation tools such as the Gail model may prove beneficial., Although, applying risk assessment models can help healthcare providers to calculate a women's risk of developing breast cancer. It has been recommended that women should have annual mammograms starting at age 40 (Min et al., 2014). In fact, women with a higher risk of developing breast cancer should get extra screening procedures; as well as they might also get beginning screening at an earlier age with more repeated periods (McPherson et al., 2000; Park et al., 2013; Bener et al., 2017).

To our knowledge, the Gail model has not been validated in a population with as large sample size as our study in Turkish women. Nevertheless, we examined the effect of factors that did not take place in the Gail model (i.e., BMI, consanguinity, duration of breast feeding, and menopausal status). In line with the findings of several studies (Gail et al., 1989; Claus et al., 1994; Costantino at al., 1999; McPherson et al., 2000; Gail 2007; Adams-Campbell et al., 2009), although our study suggested that the breast cancer risk was high in older age, presence of menopause, lower age at menarche, higher age at first birth, women with family history of breast cancer.

Furthermore, PHQ -9 and GAD-7 appears to be a reliable and valid instrument that can be used to diagnose major depression (18.5\%) and anxiety (15.2\%) among Turkish women. This is consistent the with prevalence rate of major depression and anxiety observed rates $15.4 \%$ and $14.4 \%$ in United States among women (Elrashidi et al., 2018), also similarly study reported for the depression $14.7 \%$, and anxiety $10.1 \%$ conducted in Latvia women (Ivanovs et al., 2018).

In conclusion, breast cancer is major public health issue in Turkey. For preventing and screening of breast cancer, estimation of risk of breast cancer in Turkish population is crucial., Our study indicates that Gail model is a reliable and useful breast cancer risk prediction model for clinical decision-making. The Gail et al., model fits very well in this sample in terms of predicting numbers of breast cancer cases in specific risk factor strata but had modest discriminatory accuracy at the individual level. Our study may prove beneficial in the management of breast cancer counseling provided that the results of our study validated in prospective studies.

\section{Contributors}

$\mathrm{AB}, \mathrm{CCB}$ and $\mathrm{YO}$ are designed and supervised the study and were involved in data collection, statistical analysis the writing of the paper. AA was involved in interpretation of data and writing manuscript. All authors approved the final version of this manuscript.

\section{Ethics Committee Approval}

Ethics committee approval was received for this study.

\section{Informed Consent}

Informed consent was obtained for this study.

\section{Financial Disclosure}

The authors declared that this study has received no financial support.

\section{Competing interests}

We have no financial interest to declare.

\section{Acknowledgements}

The authors would like to thank the Istanbul Medipol University, Unniversity Medipol Hospitals Complexes for their support and ethical approval (IRB \# 10840098-604.01.01-E.9283).

\section{References}

Adams-Campbell LL, Makambi KH, Frederick WA, et al (2009). Breast cancer risk assessments comparing Gail and CARE models in African-American Women. Breast J, 15, 72-5.

Andreeva VA, Pokhrel P (2013). Breast cancer screening utilization among Eastern European immigrant women worldwide: a systematic literature review and a focus on psychosocial barriers. Psychooncology, 22, 2664-75.

Bener A, Çatan F, El Ayoubi HR, Acar A, Ibrahim WH (2017). Assessing breast cancer risk estimates based on the Gail Model and its predictors in Qatari women. J Prim Care Community Health, 8, 180-7.

Bener A, El Ayoubi HR, Ali AI, Al-Kubaisi A, Al-Sulaiti H (2010). Does consanguinity lead to decreased incidence of breast cancer?. Cancer Epidemiol, 34, 413-8.

Berry DA, Iversen ES Jr, Gudbjartsson DF, et al (2002). BRCAPRO validation, sensitivity of genetic testing of BRCA1/BRCA2, and prevalence of other breast cancer susceptibility genes. J Clin Oncol, 20, 2701-12.

Claus EB, Risch N, Thompson WD (1994). Autosomal dominant inheritance of early onset breast cancer: implications for risk prediction. Cancer, 73, 643-51.

Constantino J, Gail MH, Pee D, et al (1999). Validation studies for models projecting the risk of invasive and total breast cancer incidence. J Natl Cancer Inst, 91, 1541-54.

Elrashidi MY, Philpot LM, Ramar P, Leasure WB, Ebbert JO (2018). Depression and anxiety among patients on chronic opioid therapy. Health Serv Res Manag Epidemiol, 19, 1-7.

Erbil N, Dundar N, Inan C, Bolukbas N (2015). Breast cancer risk assessment using the Gail model: A Turkish study. Asian Pac J Cancer Prev, 16, 303-6.

Gail MH, Brinton LA, Byar DP, et al (1989). Projecting individualized probabilities of developing breast cancer for white females who are being examined annually. J Natl Cancer Inst, 81, 1879-86.

Gail MH, Costantino JP, Pee D, et al (2007). Projecting individualized absolute invasive breast cancer risk in African American women. J Natl Cancer Inst, 99, 1782-92.

GLOBOCAN (2018). Estimated Cancer Incidence, Mortality and Prevalence Worldwide in 2012. http://globocan.iarc.fr/Pages/ summary_table_pop_sel.aspx. Accessed 21 August 2018.

Ivanovs R, Kivite A, Ziedonis D, et al (2018). Association of depression and anxiety with cardiovascular co-morbidity in a primary care population in Latvia: a cross-sectional study. BMC Public Health, 18, 328.

Khazaee-Pool M, Majlessi F, Nedjat S, et al (2016). Assessing breast cancer risk among Iranian women using the Gail 
Model. Asian Pac J Cancer Prev, 17, 3759-62.

Kroenke K, Spitzer RL, Williams JBW (2001). The PHQ-9. $J$ Gen Intern Med, 16, 606-13.

McPherson K, Steel C, Dixon JM (2000). Breast cancerepidemiology, risk factors, and genetics. $B M J, 9,321,624-8$.

Min JW, Chang MC, Lee HK, et al (2014). Korean breast cancer society. Validation of risk assessment models for predicting the incidence of breast cancer in Korean women. $J$ Breast Cancer, 17, 226-35.

Ministry of Health (2003): The most frequent ten cancers in females in Turkey. http://212.175.169.156/KSDB/ BelgeGoster.

Mirghafourvand M, Mohammad-Alizadeh-Charandabi S, Ahmadpour P, Rahi P (2016). Breast cancer risk based on the Gail Model and its predictors in Iranian women. Asian Pac J Cancer Prev, 17, 3741-5.

National Cancer Institute (2013). Breast Cancer Risk Assessment Tool. [Last accessed on 24.07.2018]. Available from: https:// www.cancer.gov/bcrisktool/Default.aspx.

Novotny J, Pecen L, Petruzelka L, et al (2006). Breast cancer risk assessment in the Czech female population--an adjustment of the original Gail model. Breast Cancer Res Treat, 95, 29-35.

Pace LE, Keating NL (2014). A systematic assessment of benefits and risks to guide breast cancer screening decisions. JAMA, 311, 1327-35.

Park B, Ma SH, Shin A, et al (2013). Korean risk assessment model for breast cancer risk prediction. PLoS One, 8.10, e76736.

Siegel RL, Miller KD, Jemal A (2015). Cancer statistics, 2015. CA Cancer J Clin, 5, 5-29.

Spitzer RL, Kroenke K, Williams JB, Lowe B (2006). A brief measure for assessing generalized anxiety disorder: the GAD-7. Arch Intern Med, 166, 1092-7.

Tice JA, Cummings SR, Ziv E, Kerlikowske K (2005). Mammographic breast density and the Gail model for breast cancer risk prediction in a screening population. Breast Cancer Res Treat, 94, 115-22.

Tyrer J, Duffy SW, Cuzick J (2004). A breast cancer prediction model incorporating familial and personal risk factors. Stat Med, 23, 1111-30.

Ulusoy C, Kepenekci I, Kose K, Aydintug S, Cam R (2010). Applicability of the Gail model for breast cancer risk assessment in Turkish female population and evaluation of breastfeeding as a risk factor. Breast Cancer Res Treat, 120, 419-24

Wang X, Huang Y, Li L, Dai H, Song F, Chen K (2018). Assessment of performance of the Gail model for predicting breast cancer risk: a systematic review and meta-analysis with trial sequential analysis. Breast Cancer Res, 20, 18.

World Health Organization (2014). Breast Cancer: Prevention and Control http://www.who.int/cancer/detection/breastcancer/ en/ Accessed 30 July, 2018.

\section{(ब) $(1)$}

This work is licensed under a Creative Commons AttributionNon Commercial 4.0 International License. 